
$\angle$ Research Square
Preprints are preliminary reports that have not undergone peer review.
They should not be considered conclusive, used to inform clinical practice, or referenced by the media as validated information.

\title{
SNP-based breeding for broiler resistance to ascites and evaluation of correlated production traits
}

Katie P. Lee

University of Arkansas Fayetteville

Nicholas B. Anthony

University of Arkansas Fayetteville

Sara K. Orlowski

University of Arkansas Fayetteville

Douglas Duane Rhoads ( $\nabla$ drhoads@uark.edu )

University of Arkansas Fayetteville https://orcid.org/0000-0001-7307-4754

\section{Research}

Keywords: ascites, SNP, broiler, breeding

Posted Date: September 22nd, 2021

DOI: https://doi.org/10.21203/rs.3.rs-903229/v1

License: (c) (i) This work is licensed under a Creative Commons Attribution 4.0 International License. Read Full License 


\section{Abstract}

Background The goal of this study was to evaluate marker-assisted selection (MAS) in broiler chickens using previously mapped gene regions associated with ascites syndrome incidence. The second-generation MAS products were assessed for impact on ascites phenotype and whether there were associated changes in important production traits. Previously, we used whole genome resequencing (WGR) to fine-map 28 chromosomal regions as associated with ascites phenotype in our experimental ascites broiler line (Relaxed, REL) based on a hypobaric chamber challenge. Genotypes for single nucleotide polymorphisms (SNPs) in mapped regions on chromosomes 2 and 22, were used for MAS in our REL line. After two generations, birds homozygous for the genotypes associated with resistance for both chromosomal regions were established. The MAS F2 generation was then compared to the REL line for ascites susceptibility and 25 production traits. Results Selection based on SNPs in the carboxypeptidase Q (CPQ, Gga2) and leucine rich repeat transmembrane neuronal 4 (LRRTM4, Gga22) gene regions resulted in a sex- and simulated altitude- dependent reduction of ascites incidence in two F2 cohorts of the MAS line. Comparisons of the F2 MAS and REL lines for production traits when reared at ambient pressure found no significant negative impacts for feed intake (FI), feed conversion ratio (FCR), or deboned part yields for either sex for two F2 cohorts. There were, however, improvements in the MAS for full-trial body weight gain (BWG), FCR, absolute and relative tender weights, and relative drumstick weight. Conclusions These results validate the mapping of the 28 chromosomal regions and demonstrate that fine mapping by WGR is an effective strategy for addressing a complex trait; it also stands as the first successful SNP-based selection program against a complex disease trait, such as ascites. The MAS line is comparable and, in some instances, superior, in growth performance to the REL control while being more resistant to ascites. This study indicates that MAS based on WGR can provide significant breeding potential in agricultural systems.

\section{Background}

Since the 1950s, poultry breeding programs have selected for the increased ability of broilers to rapidly accrete muscle tissue, thus minimizing grow-out time and increasing profits. There have been, however, some negative results of this genetic progress, one of which is pulmonary hypertension syndrome (PHS), or ascites. Traditionally, ascites has been associated with rearing birds at higher elevations where partial pressures of oxygen are lower [1-11], or in colder rearing environments $[12,13]$. Ascites syndrome is the terminal result of prolonged pulmonary hypertension, as liver damage releases ascitic fluid into the body cavity $[9,14,15]$. Prolonged hypertension is driven by increased oxygen demands of a rapidly growing body supplied by an inadequate cardiopulmonary system [16-18]. The incidence can be amplified as a result of an oxygen-reduced environment, or increased thermoregulation in cold environments [9, 15]. The bird's body increases blood pressure in an attempt to respond to metabolic demands, which leads to incomplete gas exchange in the lungs [15, 19-21]. Semioxygenated blood is then sent to the organs with substantial detrimental effect on the liver, causing the accumulation of abdominal fluid. It has been estimated that ascites is the cause of up to $8 \%$ of broiler mortality and accounts for up to $\$ 100,000,000$ in economic losses annually, making it both a significant animal welfare and economic concern $[6,14,15,21-25]$.

Mitigation of ascites incidence has achieved varying degrees of success typically employing i) feed restriction [1, 24, 26-31] , ii) nutrient density modification to reduce protein [29,31-33], or iii) feed additives such as arginine or antioxidants [29, 30, 34-37]. Several of the methods for reducing ascites simply slow growth and negatively affect flock production performance. Variability of efficacy found in these mitigation methods can result from genetic differences between commercial lines, environmental variations due to geography, and flock management. As ascites is estimated to have a relatively high heritability with reports ranging from 0.22 to 0.41 , it is logical that increased ascites resistance through genetic selection could have significant advantages and increase production potential $[4,11,38-40]$.

Previous research at the University of Arkansas on the genetic basis of ascites involved the development of three research lines from a commercial elite line through divergent selection for ascites resistance when exposed to simulated high elevation conditions [11]. The base population (Relaxed, REL) for the selection study was derived from a commercial elite line in the 1990s and maintained through random mating without selection. Sib-selection based on ascites phenotype assessed through a 6-week hypobaric chamber challenge produced ascites resistant (RES) and ascites susceptible (SUS) lines. Rapid response in divergent selection with successive generations suggested a limited number of major genes. A series of genome-wide association studies (GWAS) using SNP panels identified a few candidate SNPs as associated with ascites phenotype, but subsequent MAS-based breeding projects were unsuccessful in validating these few loci [41-44]. More recently, whole genome resequencing (WGR) identified 28 genomic regions where SNP clusters (100s to 1000s of SNPs) showed frequency bias with respect to ascites phenotype $[45,46]$. Two of these regions were validated by further genotyping of additional DNA samples and found to have potential epistatic interaction. One region spanned more than $120 \mathrm{kbp}$ on chromosome 2 including the $3^{\prime}$ end of the gene for carboxypeptidase $\mathrm{Q}(\mathrm{CPQ})$. The second was an approximately $50 \mathrm{kbp}$ region on chromosome 22 spanning the $3^{\prime}$ end of the gene for leucine-rich repeat transmembrane neuronal 4 (LRRTM4). Both these genes have been associated in human GWAS with blood traits, heart rate, and blood pressure consistent with factors contributing to ascites incidence in poultry.

Therefore, the current study reports on whether MAS based on SNP genotypes for the regions of both CPQ and LRRTM4 can produce offspring with greater innate ascites resistance. Since ascites susceptibility could potentially be linked to important production traits, we also assessed the impact of selection on important broiler production traits.

\section{Methods}

All breeding, hatching, grow-out, and processing took place at the University of Arkansas Poultry Research farm. All animal procedures were approved by the University of Arkansas Institutional Animal Care and Use Committee (Approval Numbers 18083 and 18088).

\section{Bleeding, genotyping, and husbandry of breeder stock}


Birds used for breeding were genotyped by collecting $10 \mu \mathrm{l}$ of blood from the brachial vein which was further processed using a rapid DNA extraction method [47]. These DNAs were then genotyped using exonuclease assays run in triplicate for both CPQ and LRRTM4 genes, as described [45, 46]. Selected breeders were then moved into individual breeder cages for insemination and production of MAS offspring. At 18 weeks of age, the birds were put on a lighting schedule to induce egg production: a starting schedule of 12 hours light:12 hours dark that progressed for 4 weeks to 16 hours light: 8 hours dark, which was maintained through the insemination/egg collection period. Insemination occurred two times weekly, and eggs were collected daily and were labeled by hen. All eggs were stored at $18^{\circ} \mathrm{C}$ and $60 \%$ relative humidity until sufficient numbers were reached to begin hatching the next generation.

\section{Hatchery protocol}

Sets of eggs were placed in a setting incubator (Jamesway Incubator Co., Cambridge, Ontario, Canada) at $99.6^{\circ} \mathrm{F}$ and $85 \%$ relative humidity for 18 days. On d 18 , the eggs were candled, infertile eggs removed, fertile eggs placed into hatch baskets, and transferred by mating combination to a hatching incubator (Jamesway Incubator Co.) at $98.0^{\circ} \mathrm{F}$ and $88 \%$ relative humidity. On d 21 , hatched chicks were wing-banded using different band colors for each subpopulation, and individual band numbers recorded.

\section{Hypobaric trials}

For both hypobaric cohorts, birds of each line (MAS and REL) were mixed in one of 40 battery cages (measuring $0.6 \times 0.6 \times 0.3 \mathrm{~m}$ ) with appropriate numbers from each line to maintain even distribution throughout all the cages. No mortality data other than wing band number was collected for the first week so that final mortality rates would not be confounded by chicks that failed to start. For the remaining four weeks of the trial, the husbandry and necropsy methods followed those described previously $[11,41,44]$. As the birds grew, bird densities were reduced in cages to maintain compliance with animal welfare requirements. Birds were initially chosen for removal due to observation of clinical ascites phenotype through palpation of the abdomen. All birds removed were euthanized and subsequently necropsied for ascites phenotype. Once all birds showing ascites phenotype had been removed, additional birds were chosen at random to meet welfare requirements and maintain consistent numbers for both lines. All birds remaining at the end of 5 weeks were euthanized and necropsied to determine ascites phenotype.

\section{Floor trials}

Hatches were placed in floor pens that were top-dressed with fresh pine shavings. Similar numbers or each line were placed at similar densities. Surplus chicks were placed in a separate pen. Cardboard trays for feed were placed and remained in the pens for the first 7 days of the trial. Feed and water were provided ad libitum throughout the trial. One continuous water line per row of pens was adjusted as needed for bird height. Health inspections occurred twice daily at a minimum. All mortalities were removed upon discovery and wing band number, pen of origin, body weight, and any clinical observations including ascites incidence were recorded. If available, the bird was replaced with another of the same sex and genetic line from the surplus birds. Feed was formulated to Cobb-Vantress, Inc., industry recommended standards (formulations can be found in Table 1) and was added as needed throughout the trial. Feeding phases were as follows: starter from placement to $d 14$, finisher from $d 14$ to $d 35$, and withdrawal from $d 35$ to $d 55$. Pen weights were collected at time of placement, $d$ 14, d 28, $d$ 42, and d 49. Feed intake and feed conversion ratio (FCR) were recorded from d 49 until processing.

\section{Processing}

The day prior to processing, a subset of each cohort consisting of 25 males and 25 females per genetic line ( $\mathrm{n}=100$ per cohort) were randomly selected. These birds were removed from the pen first on the morning of processing and were removed from the processing line prior to evisceration to be necropsied for organ weights of liver, lungs (set), spleen, and heart, as well as RVTV. These birds were not chilled or deboned. Also on the day prior to processing, a second subset from each cohort were randomly chosen, consisting of 50 males and 50 females per genetic line ( $n=200$ per cohort). These birds were wing-banded to be assessed for MAS impact on meat quality measurements of the breast fillet. Feed was removed 10 hours prior to processing to ensure feed passage. All birds were collected the morning of processing and transported to the University of Arkansas Poultry Pilot Processing Plant. At the processing plant, back dock live weight was collected prior to the birds being electrically stunned and exsanguinated, followed by a scalding water bath to loosen feathers, then feather, head, and paw removal. Carcasses were then eviscerated, and the hot carcass and fat pad weights were collected. Carcasses were chilled for 3 hours and deboned thereafter for the determination of absolute weight and relative (to back dock live weight) yield of wings, breasts, tenders, thighs, and drumsticks. The 200 carcasses marked for further evaluation were processed as described but also evaluated for muscle quality traits including breast fillet weight, color, and pH at 4- and 24-hours chill time. The deviation between the 4- and 24-hour fillet weights were used to calculate drip loss. Color and pH were measured using a Minolta CR-400 handheld model with PC-linked SpectramagicX software and Testo model 205 handheld spear-tip probe, respectively. Color readings were taken on the dorsal surface of the breast, while $\mathrm{pH}$ was measured in the cranial region of the breast. The breasts were then frozen until the completion of both trials for cooking and shear force measurements. Shear requirements were calculated based on four measurements in the cranial region using a TA.XTP/us equipped with a Meullenet-Owens Razor Shear head attachment.

\section{Statistical Methods}

All statistical analyses other than the survival model were conducted in $\mathrm{R}$ with statistical significance denoted by a $P$-value $\leq 0.05$.

Hypobaric mortality data were analyzed using a generalized linear model of final ascites mortality as well as a survival model which showed the effect of genetic line and sex on the probability of survival over time.

Live performance data were analyzed using two-way ANOVA between the main effects of trial and genetic line. Parts weights, organ weights, heart characteristic, and meat quality characteristic data from processing were analyzed using three-way ANOVA between the main effects of trial, genetic line, and sex. All means were separated by Tukey's Honest Significant Difference (HSD) test. 


\section{Results}

\section{First-generation breeding}

Breeders for the first parent generation were selected from REL breeder stock in July of 2018. After bleeding and genotyping, two $P_{0}$ crosses were then created: one consisting of birds with all non-reference SNPs (compared to galGal6, [46]) for each gene region, designated $P_{0}-1$, and the other consisting of birds with non-reference SNPs for CPQ and heterozygous SNPs for LRRTM4, designated $P_{0}-2$. $P_{0}-1$ consisted of 10 males and 13 females; $P_{0}-2$ consisted of 12 males and 24 females. Separately, ungenotyped REL birds were used to breed generation 1 of the control population. Semen was collected from all the males of each $\mathrm{P}_{0}$ group, pooled, and used to artificially inseminate each of the females from the same $\mathrm{P}_{0}$ group.

\section{Second-generation breeding}

After hatching, the $\mathrm{F}_{1}$ progeny produced from $\mathrm{P}_{0}-1$ and $\mathrm{P}_{0}-2$ were kept in floor pens and managed as breeders until they reached 18 weeks of age, at which point they were then bled and genotyped. Breeders for each F1 population were placed in individual breeder cages and photo stimulated. In May of 2019, breeders from the $F_{1}$ were selected based on being homozygous for the non-reference SNPs for both genes; though all breeder SNP genotypes from this point forward were the same, the F1 populations were kept separate in order to complete reciprocal matings between them. Breeders from $F_{1}-1$ (from $P_{0}-1$ ) consisted of 12 males and 31 females; $F_{1}-2$ (from $P_{0}-2$ ) consisted of 12 males and 37 females. To produce the control group, 24 males and 72 females from the REL line were also utilized. Insemination began at the same time, when the MAS breeders were 22 weeks of age and the REL control breeders were 20 weeks of age. For the REL, pooled semen from all 24 males were used to artificially inseminate all 72 REL females. For the MAS, pooled semen from the $F_{1}-1$ males was used to artificially inseminate the $F_{1}-2$ females and similarly the $F_{1}-2$ males were used to inseminate the $F_{1}-1$ females. This reciprocal mating scheme produced the F2 generation of birds which would possess only the non-reference SNPs for the CPQ and LRRTM4 genes. Sets of eggs for hatching included at least 250 eggs each from REL and the $F_{2}$ of the MAS. At transfer, all eggs were candled and infertile or eggs with embryonic mortality were removed and stored for breakout on hatch day along with eggs that did not hatch; no significant difference $(P>0.05)$ in hatchery breakout was found between the two lines. After hatch, birds received a wing band that represented their genetic line (either MAS or REL). Sets of eggs were produced every two weeks for four total hatches. The first and fourth hatches were subjected to 5-week hypobaric challenges. The second and third hatches were placed for 8-week floor pen trials to evaluate change in production traits associated with MAS.

\section{Hypobaric challenges}

F2 chicks for challenge in the hypobaric (Hypo) chamber were placed on November 28, 2019 (Hypo1) and January 8, 2020 (Hypo2). Hypo1 was maintained at $9,000 \mathrm{ft}$ simulated altitude while Hypo2 was initially set at 9,000 ft simulated altitude, then after 2 weeks increased to $11,000 \mathrm{ft}$ simulated elevation to induce a higher incidence of ascites. In Hypo1, all hatched birds were placed in the chamber $(n=578)$ whereas in Hypo2, similar numbers of birds were placed from each line and fewer total birds were placed $(n=433)$ which reduced the number of birds that would need to be culled for compliance with bird density regulations.

The hypobaric challenge results indicate a sex-and elevation-dependent reduction in ascites incidence in both cohorts. Hypo1 saw an overall decrease $(P=0.041)$ in ascites mortality between the MAS and REL birds, with a $27.3 \%$ reduction for ascites in MAS males and a $39.8 \%$ in MAS females [Table 2 ]. For Hypo2, there was an overall numerical, although not statistically significant $(P=0.162)$, decrease in ascites mortality between the lines, with reductions of $23.4 \%$ in males $(P=0.126)$ and only $5.2 \%$ reduction in females [Table 1 ]. There was no significant difference $(P>0.05)$ between the lines for the right ventricle to total ventricle (RVTV) ratio or body weight. The Kaplan-Meier survival model curve visually echoes these trends, however the analyzed $\mathrm{P}$-values from this model are only numerically different $(P>0.05)$ [Figure 1].

\section{Floor trials}

Birds reared for the floor trials were placed on December 12, 2019 (Floor1) and December 28, 2019 (Floor2). On the day of placement, the total number of hatched birds was counted for each line and the number of birds placed per pen determined based on the smallest group; for Floor 1 this was 14 birds per pen $\left(0.133 \mathrm{~m}^{2} / \mathrm{bird}\right)$ and for Floor 13 birds per pen $\left(0.143 \mathrm{~m}^{2} / \mathrm{bird}\right)$ with all excess birds placed in spare pens for mortality replacement up until the beginning of the FCR measurement period from d 49 to $d 55$. As both floor trials were run concurrently in the same barn, though offset by two weeks, we considered whether the live performance and processing data should be analyzed as completely separate trials with separate analyses or together by adding the main effect of trial. After consultation with a professional agricultural statistician and colleagues at the University of Arkansas, the latter option was chosen. However, the interaction between line and trial was assessed for each measurement, and any traits identified as having an interaction between line and trial were noted and are discussed. Conclusions about the overall affect of MAS on that particular measurement were not drawn in those cases.

Live performance data from both cohorts is shown in Table 3. Significant differences were found between trials: d0 body weight (BW) ( $<<0.001)$, d42 BW $(P=0.038)$, d0-42 body weight gain (BWG) $(P=0.045)$, d49 BW $(P=0.006)$, d0-49 BWG $(P=0.007)$, d54 BW $(P=0.017)$, and full-trial BWG $(P=0.019)$. Additionally, the genetic lines were significantly different in d49-54 BWG $(P=0.036)$ and FCR $(P<0.001)$, both of which were improved in the MAS. Significant differences were found between trial and genetic line for d14 BW $(P=0.019)$ and d0-14 BWG $(P=0.015)$.

\section{Processing}

Total sample sizes and tabular representations of the data are as follows: Table 4, live weight and carcass characteristics ( $\mathrm{n}=868$ ); Table 5, deboned parts $(n=868)$; Table 6, organ weights $(n=295)$; Table 7, heart characteristics $(n=295)$; Table 8, meat quality characteristics $(n=395)$. A significant improvement was seen in the MAS birds for absolute and relative tender weights $(P<0.001, P<0.001$, respectively), relative drumstick weight $(P=0.016)$, and significant differences were found for 24 -hour $L^{*}$ color measurement $(P<0.001)$, 24-hour a* color measurement $(P=0.037)$, and 24-hour $p H(P=0.003)$. Significant 
differences were found between sexes in relative hot carcass weight $(P<0.001)$, wing weight $(P<0.001)$, relative thigh weight $(P<0.001)$, relative drumstick weight $(P<0.001)$, absolute and relative heart weight $(P<0.001, P=0.018$, respectively), liver weight $(P<0.001)$, lung weight $(P<0.001)$, spleen weight $(P<0.001)$, RV weight $(P<0.001)$, TV weight $(P<0.001)$, drip loss $(P<0.001)$, 24-hour $L^{*}$ color measurement $(P<0.001)$, 24-hour pH $(P<0.001)$, and shearing peaks $(P=0.016)$.

Significant differences were also found between the two floor trials for many characteristics, including wing weight $(P<0.001)$, relative breast weight $(P<0.001)$, relative thigh weight $(P<0.001)$, relative drumstick weight $(P=0.002)$, relative heart weight $(P<0.001)$, liver weight $(P=0.009)$, relative spleen weight $(P=0.014)$, 24-hour a* color measurement ( $P=0.003)$, 24-hour $b^{*}$ color measurement $(P=0.017)$, 24-hour $p H(P<0.001)$, and shearing peaks $(P=0.002)$. Due to this, there were also several significant interactions. Between trial and genetic line, significant differences were found for RV weight $(P=0.046), R V T V(P=0.005)$, shear force requirement $(P<0.001)$, and 1:3 shear area $(P<0.001)$. While RV was found to be significantly different, Tukey's HSD test was unable to separate the means. RVTV was found to be the largest in MAS birds from both trials and the smallest in REL birds from both trials. The largest shear force measurements were found in the Floor2 REL breasts, with intermediate force requirements in the Floor1 MAS group, and the lowest requirements in the Floor1 REL and Floor2 MAS groups. The largest 1:3 shear area measurements were found in the Floor2 REL group, with all other groups having comparable lower measurements.

A number of significant differences were found between trial and sex. These were live weight $(P=0.035)$, hot carcass weight $(P=0.028)$, fat pad weight $(P=0.019)$, chilled carcass weight $(P=0.036)$, absolute and relative tender weight $(P=0.010, P=0.014$, respectively $)$, thigh weight $(P=0.025)$, drumstick weight $(P=0.032)$, relative liver weight $(P=0.032)$, shear force requirement $(P=0.010)$, and $1: 3$ shear area $(P=0.040)$. The live weight and weights of hot carcass, chilled carcass, and tenders were the largest for the Floor 1 males, moderate for Floor2 males, and smallest for females in both trials. The largest fat pads were found in the Floor 1 males, moderate for Floor 1 females, small intermediate for Floor2 females, and smallest in Floor2 males. Relative tender weight was found to be the greatest in Floor2 females, moderate in Floor1 females, and the lowest in males from both trials. The mean weights of thighs and drumsticks were separated into four distinct groups, from largest to smallest being Floor1 males, Floor2 males, Floor1 females, and Floor2 females. The relative weight of liver was found to be the largest in females from both trials and the smallest in males from both trials. For both the shear force requirement and the 1:3 shear area, the measurements from Floor1 females were found to be the largest, the Floor1 males were found to be the smallest, and both sexes in Floor2 were intermediate.

Finally, there were interactions found between genetic line and sex. These were live weight $(P=0.011)$ hot carcass weight $(P=0.012)$, chilled carcass weight $(P=0.019)$, breast weight $(P=0.050)$, thigh weight $(P=0.006)$, drumstick weight $(P=0.032)$, and 24 -hour $b$ * color measurement $(P=0.025)$. For live weight and the weights of hot carcass, chilled carcass, thighs, and drumsticks, MAS males were found to be the largest, REL males were intermediate, and females from both the MAS and REL lines were found to be the smallest. Breast weight was the largest for males from both the MAS and REL lines, with the smallest weight in the females from both lines. The 24-hour $b^{*}$ color measurement was found to be the highest in MAS females, with the three other groups having comparable lower $b^{*}$ measurements.

There was also a single three-way interaction $(\mathrm{P}=0.039)$ found for the processing measurements, which was fat pad. In order from largest to smallest, the means were separated as follows: Floor1 MAS females, Floor1 REL females, Floor2 females from both lines, Floor1 REL males, Floor1 MAS males, Floor2 MAS males, and Floor2 REL males.

\section{Discussion}

Ascites has been reported to have a significant sex-dependent incidence in flocks [39, 48]. In the REL line, females show an earlier onset and higher overall incidence of ascites [11]. However, a reduction of ascites incidence was observed between MAS females of the first and fourth cohorts for hypobaric challenges where the simulated altitude differed. At moderate elevations (9,000 ft) in Hypo1, ascites incidence was reduced by nearly $40 \% \mathrm{for}$ the MAS females, while at higher simulated altitude $(11,000 \mathrm{ft})$ in Hypo2, there was only a $5 \%$ reduction of female mortality from $61.9 \%$ in the REL line to $58.7 \%$ in the MAS line. For males, incidence was reduced in the MAS line by $27 \%$ in Hypo1, while being reduced by $23 \%$ in Hypo 2 with the increased simulated altitude. This further demonstrates the sex-linked nature of ascites resistance or susceptibility and suggests more research into epistasis with genes on the sex chromosomes are warranted. Additional research into the impact of MAS on each sex is also warranted. The timeline of this study, and the capacity of the hypobaric chamber, did not allow for single-sex experiments to allow for greater sample sizes. However, even with relatively small cohort sizes, significant reduction of ascites for the MAS line was observed.

An additional point of success in these results comes from the lack of impact on production traits. If MAS negatively impacted economically important traits in any major way, then MAS would be much less appealing to the industry. From the live production data, a significant improvement of the MAS was found in body weight gain from the full trial and in FCR. A limited number of traits showed significant differences between overall MAS and REL averages, all of which were improved in the MAS birds; these were absolute and relative tender weights and relative drumstick weight. Additionally, there were some improvements in the MAS that were only seen in one sex. These were live weight, hot carcass, chilled carcass, thigh weight, and drumstick weight, all of which were larger in MAS males over REL males while the MAS and REL female measurements in each of these cases were statistically equivalent. Given these improvements, MAS appears to be not only capable of reducing ascites incidence, but to have a positive impact on some growth characteristics. Notably, there was a significant three-way interaction between trial, genetic line, and sex for fat pad weight relative to back-dock live weight. From the trend in this characteristic, we observed that the females from each cohort had larger relative fat pad weights than the males, but as this did not have an impact on the trends of the deboned parts data, we are less concerned about this outcome.

We also identified differences between MAS and REL for breast color measurements. The measurement of each breast fillet was broken into three components: $L^{*}$ represents the lightness from 0 (black) to 100 (white); $a^{*}$ represents the color spectrum from -60 (green) to +60 (red); $b^{*}$ represents the color spectrum from -60 (blue) to +60 (yellow) (American Meat Science Association, 2012). A significant difference was found in the $L^{\star}$ and $a^{\star}$ measurements 
between the two genetic lines, and in the $L^{*}$ measurement between the sexes. The difference in $L^{*}$ measurements between the two genetic lines is especially interesting as this means that MAS line breast fillets were consistently lighter in color than the REL. While the classification of Qiao et al. [49] considers all of the $L^{*}$ measurements from both cohorts except for MAS female to be "normal" in lightness (MAS female would be classified as "lighter than normal"). This color difference is difficult to visually discern, however fillets with higher $L^{*}$ values may have higher moisture contents. Thus, the fillets from MAS may have consistently greater moisture than the REL. The data also showed an interaction between genetic line and sex with the $b^{\star}$ measurement. However, other changes occurred that were only numeric; some measurements increased nearly one unit between the two cohorts, others changed which group had a greater value for a particular measurement. These variations could trace back to minor differences in formulation of individual batches of feed used for the two trials or to other causes still unknown. While these are relatively small fluctuations, it is difficult to know exactly how much of an impact it might have on consumer perspective of the color of these fillets [50].

These data validate the WGR approach for identifying regions for MAS for improving multigene traits in commercial breeding programs. However, there are limitations. One limitation is that the regions we identified in REL by WGR may not be relevant in current elite lines. The REL is the unselected descendant from a commercial elite line from the 1990s [11]. The genetics of modern elite broiler lines have undoubtedly changed in the ensuing two decades. WGR for ascites in two current commercial broiler crosses did not find associations with either the CPQ or LRRTM4 regions (unpublished). Current elite lines could be subjected to WGR using the hypobaric chamber challenge to identify line-specific regions associated with ascites phenotype. Despite the unique and proprietary nature of each commercial line, each could be assessed individually, candidate gene regions validated, and then informative regions included in selection programs. Alternatively, commercial broilers could be subjected to WGR to identify the regions to be selected for in the elite lines to produce the required genetics in the terminal cross for production of those broiler products. Further research and MAS projects for the major modern commercial crosses are needed to fully understand the efficacy of this method against ascites.

Though its prevalence in the US market varies by specific commercial products (unpublished data) and geographical region, ascites still remains problematic in the global market given worldwide variation in climates, elevations, and management strategies. Published data for mortality and economic impact are nearing or surpass two decades old [21,25], warranting new assessments of the impact on the US and global markets. Based on existing statistics, significant reduction could potentially prevent millions of bird deaths, saving millions of dollars for the industry. Our results document that genetics can be used to significantly reduce ascites without compromising production.

\section{Conclusions}

These results represent the first documented success in fine-mapping and marker-assisted selection for a complex trait in a poultry species. WGR has the potential to not only identify other genetic regions for selection against ascites, but also for other complex traits. One problem with general selection against ascites is the tendency for smaller birds to be more resistant to the disease [32, 51], meaning strictly phenotype-based selection could negatively impact growth rate and feed efficiency. Given the specificity of the regions utilized in our MAS experiment, there is a strong potential that they could be easily integrated into the current breeding programs of poultry genetics companies. This could increase innate resistance to ascites without having to "back-track" over years of selection for growth traits. WGR and MAS hold great promise for targeted genetic selection in agricultural systems.

\section{Declarations}

Ethics approval and consent to participate

All animal procedures were approved by the University of Arkansas Institutional Animal Care and Use Committee (Approval numbers 18083 and 18088 ).

Consent for publication

Not applicable

Availability of data and material

The datasets used and/or analyzed during the current study are available from the corresponding author on reasonable request.

Competing interests

The authors declare that they have no competing interests.

Funding

This project was supported by Agriculture and Food Research Initiative Competitive Grants no. 2015-67015-22960 and 2018-67015-28244 from the USDA National Institute of Food and Agriculture from the USDA National Institute of Food and Agriculture to DR, SO, and NA. Additional support was from the Arkansas Biosciences Institute, a part of the Arkansas Tobacco Settlement Act. The funders had no role in study design, data collection and analysis, decision to publish, or preparation of the manuscript.

Authors' contributions

DR, NA, KL conceived and designed the analyses; KL, NA, SO collected the data; KL, DR performed the analyses; KL wrote the manuscript; DR, SO, NA edited the manuscript. 
Acknowledgements

The authors would like to gratefully acknowledge Joseph Hiltz and the other members of the poultry genetics group in the University of Arkansas Department of Poultry Science for their work on breeding and the management of parent flocks, Dr. John Tipton for his work on the ascites mortality survival model, and the members of the "farm crew", processing plant staff, and Rhoads' Research Group for contributions to the collection of data and completion of this project.

\section{References}

1. Balog JM, Anthony NB, Cooper MA, Kidd BD, Huff GR, Huff WE, et al. Ascites syndrome and related pathologies in feed restricted broilers raised in a hypobaric chamber. Poult Sci. 2000;79(3):318-23; doi: 10.1093/ps/79.3.318.

2. Cueva S, Sillau H, Valenzuela A, Ploog H. High altitude induced pulmonary hypertension and right heart failure in broiler chickens. Res Vet Sci. 1974;16(3):370-4.

3. de los Santos SF, Tellez G, Farnell MB, Balog JM, Anthony NB, Pavlidis HO, et al. Hypobaric hypoxia in ascites resistant and susceptible broiler genetic lines influences gut morphology. Poult Sci. 2005;84(9):1495-8.

4. Druyan S, Ben-David A, Cahaner A. Development of ascites-resistant and ascites-susceptible broiler lines. Poult Sci. 2007;86(5):811-22.

5. Ghazani MHM, Karami AR, Ahmadzadeh AR, Dolgharisharaf J. Relation Between the Incidence of Ascites Syndrome and the Ventilation Factor in Broiler Chickens. Asian J Anim Vet Adv. 2008;3(5):334-6; doi: 10.3923/ajava.2008.334.336.

6. Hassanzadeh M, Buyse J, Toloei T, Decuypere E. Ascites Syndrome in Broiler Chickens: A Review on the Aspect of Endogenous and Exogenous Factors Interactions. J Poult Sci. 2014;51(3):229-41; doi: 10.2141/jpsa.0130063.

7. Hernandez A. Hypoxic ascites in broilers: A review of several studies done in Colombia. Avian Dis. 1987:658-61.

8. Huchzermeyer FW. Broiler ascites: a review of the ascites work done at the poultry section of the Onderstepoort Veterinary Institute 1981-1990. Worlds Poult Sci J. 2012;68(1):41-50; doi: 10.1017/S0043933912000050.

9. Julian RJ. The Response of the Heart and Pulmonary Arteries to Hypoxia, Pressure, and Volume. A Short Review. Poult Sci. 2007;86(5):1006-11; doi:https://doi.org/10.1093/ps/86.5.1006.

10. Owen R, Wideman Jr R, Hattel A, Cowen B. Use of a hypobaric chamber as a model system for investigating ascites in broilers. Avian Dis. 1990;34(3):7548; doi: $10.2307 / 1591275$.

11. Pavlidis HO, Balog JM, Stamps LK, Hughes JD, Jr., Huff WE, Anthony NB. Divergent selection for ascites incidence in chickens. Poult Sci. 2007;86(12):2517-29; doi: 10.3382/ps.2007-00134.

12. Lubritz DL, McPherson BN. Effect of Genotype and Cold Stress on Incidence of Ascites in Cockerels. J Appl Poult Res. 1994;3(2):171-8; doi: 10.1093/japr/3.2.171.

13. Ipek A, Sahan U. Effects of Cold Stress on Broiler Performance and Ascites Susceptibility. Asian-Australas J Anim Sci. 2006;19(5):734-8; doi: $10.5713 /$ ajas.2006.734.

14. Julian RJ. Production and growth related disorders and other metabolic diseases of poultry - A review. Vet J. 2005;169:350-69.

15. Wideman RF, Rhoads DD, Erf GF, Anthony NB. Pulmonary arterial hypertension (ascites syndrome) in broilers: A review. Poult Sci. 2013;92(1):64-83; doi: 10.3382/ps.2012-02745.

16. Wideman RF. Cardio-pulmonary hemodynamics and ascites in broiler chickens. Avian Biol Res. 2000;11(1):21-44.

17. Wideman RF. Pathophysiology of heart/lung disorders: pulmonary hypertension syndrome in broiler chickens. Worlds Poult Sci J. 2001;57(3):289-307; doi: 10.1079/WPS20010021.

18. Wideman RF, Chapman ME, Hamal KR, Bowen OT, Lorenzoni AG, Erf GF, et al. An inadequate pulmonary vascular capacity and susceptibility to pulmonary arterial hypertension in broilers. Poult Sci. 2007;86(5):984-98.

19. Henry JD, Fedde MR. Pulmonary Circulation Time in the Chicken. Poult Sci. 1970;49(5):1286-90; doi: 10.3382/ps.0491286.

20. Huchzermeyer F, De Ruyck A. Pulmonary hypertension syndrome associated with ascites in broilers. Vet Rec. 1986;119(4):94-; doi: 10.1136/vr.119.4.94.

21. Julian RJ. Ascites in poultry. Avian Pathol. 1993;22(3):419-54.

22. Haron A, Ruzal M, Shinder D, Druyan S. Hypoxia during incubation and its effects on broiler's embryonic development. Poult Sci. 2021; doi:

10.1016/j.psj.2020.12.048.

Page $7 / 20$ 
23. Olkowski AA, Wojnarowicz C, Laarveld B. Pathophysiology and pathological remodelling associated with dilated cardiomyopathy in broiler chickens predisposed to heart pump failure. Avian Pathol. 2020:1-12; doi: 10.1080/03079457.2020.1757620.

24. Rajani J, Karimi Torshizi MA, Rahimi S. Control of ascites mortality and improved performance and meat shelf-life in broilers using feed adjuncts with presumed antioxidant activity. Anim Feed Sci Technol. 2011;170(3):239-45; doi: 10.1016/j.anifeedsci.2011.09.001.

25. Odom T. Ascites syndrome: overview and update. Poultry Digest. 1993;52(1):14-22.

26. Acar N, Sizemore F, Leach G, Wideman R, Owen R, Barbato G. Growth of broiler chickens in response to feed restriction regimens to reduce ascites. Poult Sci. 1995;74(5):833-43.

27. Arce J, Berger M, Coello CL. Control of Ascites Syndrome By Feed Restriction Techniques. J Appl Poult Res. 1992;1(1):1-5; doi: 10.1093/japr/1.1.1.

28. Fedde MR, Weigle GE, Wideman RF. Influence of feed deprivation on ventilation and gas exchange in broilers: relationship to pulmonary hypertension syndrome. Poult Sci. 1998;77(11):1704-10; doi:https://doi.org/10.1093/ps/77.11.1704.

29. Baghbanzadeh A, Decuypere E. Ascites syndrome in broilers: physiological and nutritional perspectives. Avian Pathol. 2008;37(2):117-26; doi: $10.1080 / 03079450801902062$.

30. Khajali F, Wideman RF. Nutritional approaches to ameliorate pulmonary hypertension in broiler chickens. J Anim Physiol Anim Nutr (Berl). 2016;100(1):314; doi:https://doi.org/10.1111/jpn.12315.

31. Camacho-Fernández D, López C, Ávila E, Arce J. Evaluation of Different Dietary Treatments to Reduce Ascites Syndrome and Their Effects on Corporal Characteristics in Broiler Chickens. J Appl Poult Res. 2002;11(2):164-74; doi: 10.1093/japr/11.2.164.

32. Julian RJ. Physiological, management and environmental triggers of the ascites syndrome: A review. Avian Pathol. 2000;29:519-27.

33. Behrooj N, Khajali F, Hassanpour H. Feeding reduced-protein diets to broilers subjected to hypobaric hypoxia is associated with the development of pulmonary hypertension syndrome. Br Poult Sci. 2012;53(5):658-64; doi: 10.1080/00071668.2012.727082.

34. Ruiz-Feria CA, Kidd MT, Wideman RF. Plasma Levels of Arginine, Ornithine, and Urea and Growth Performance of Broilers Fed Supplemental L-Arginine During Cool Temperature Exposure. Poult Sci. 2001;80(3):358-69; doi: 10.1093/ps/80.3.358.

35. Ruiz-Feria CA. Concurrent supplementation of arginine, vitamin E, and vitamin C improve cardiopulmonary performance in broilers chickens. Poult Sci. 2009;88(3):526-35; doi:https://doi.org/10.3382/ps.2008-00401.

36. Bautista-Ortega J, Ruiz-Feria CA. I-Arginine and antioxidant vitamins E and C improve the cardiovascular performance of broiler chickens grown under chronic hypobaric hypoxia. Poult Sci. 2010;89(10):2141-6; doi: 10.3382/ps.2010-00764.

37. Faraji M, Karimi Dehkordi S, Zamiani Moghadam AK, Ahmadipour B, Khajali F. Combined effects of guanidinoacetic acid, coenzyme Q10 and taurine on growth performance, gene expression and ascites mortality in broiler chickens. J Anim Physiol Anim Nutr (Berl). 2019;103(1):162-9; doi: 10.1111/jpn.13020.

38. Lubritz DL, Smith JL, McPherson BN. Heritability of ascites and the ratio of right to total ventricle weight in broiler breeder male lines. Poult Sci. 1995;74(7):1237-41; doi: 10.3382/ps.0741237.

39. Moghadam H, McMillan I, Chambers, Julian R. Estimation of genetic parameters for ascites syndrome in broiler chickens. Poult Sci. 2001;80(7):844-8.

40. Pakdel A, Van Arendonk J, Vereijken A, Bovenhuis H. Direct and maternal genetic effects for ascites-related traits in broilers. Poult Sci. 2002;81(9):1273-9; doi: $10.1093 / \mathrm{ps} / 81.9 .1273$.

41. Krishnamoorthy S, Smith CD, Al-Rubaye AA, Erf GF, Wideman RF, Anthony NB, et al. A quantitative trait locus for ascites on chromosome 9 in broiler chicken lines. Poult Sci. 2014;93(2):307-17; doi: 10.3382/ps.2013-03359.

42. Dey S, Krishna S, Anthony NB, Rhoads DD. Further investigation of a quantitative trait locus for ascites on chromosome 9 in broiler chicken lines. Poult Sci. 2017;96(4):788-97.

43. Krishna S, Tarrant KJ, Rhoads DD, Anthony NB. Effects of a chromosome 9 quantitative trait locus for ascites on economically important traits in broilers. Poult Sci. 2017;96(9):3039-42; doi: 10.3382/ps/pex154.

44. Tarrant KJ, Dey S, Kinney R, Anthony NB, Rhoads DD. Multi-generational genome wide association studies identify chromosomal regions associated with ascites phenotype. Poult Sci. 2017;96(6):1544-52; doi: 10.3382/ps/pew478.

45. Parveen A, Jackson C, Dey S, Tarrant KJ, Anthony NB, Rhoads DD. Identification and validation of quantitative trait loci for ascites in broilers using whole genome resequencing. BMC Genet. 2020;21:54.

46. Dey S, Parveen A, Tarrant KJ, Licknack T, Kong B, Anthony NB, et al. Whole Genome Resequencing Identifies the $C P Q$ Gene as a Determinant of Ascites Syndrome in Broilers. PLoS One. 2018;13(1):e0189544; doi: 10.1371/journal.pone.0189544. 
47. Bailes S, Devers J, Kirby JD, Rhoads D. An inexpensive, simple protocol for DNA isolation from blood for high-throughput genotyping by polymerase chain reaction or restriction endonuclease digestion. Poult Sci. 2007;86:102-6.

48. Closter AM, van As P, Elferink MG, Crooijmanns RPMA, Groenen MAM, Vereijken ALJ, et al. Genetic correlation between heart ratio and body weight as a function of ascites frequency in broilers split up into sex and health status. Poult Sci. 2012;91(3):556-64; doi: 10.3382/ps.2011-01794.

49. Qiao M, Fletcher DL, Smith DP, Northcutt JK. The Effect of Broiler Breast Meat Color on pH, Moisture, Water-Holding Capacity, and Emulsification Capacity. Poult Sci. 2001;80(5):676-80; doi: 10.1093/ps/80.5.676.

50. Font-i-Furnols M, Guerrero L. Consumer preference, behavior and perception about meat and meat products: An overview. Meat Sci. 2014;98(3):361-71; doi: 10.1016/j.meatsci.2014.06.025.

51. Balog JM, Kidd BD, Huff WE, Huff GR, Rath NC, Anthony NB. Effect of cold stress on broilers selected for resistance or susceptibility to ascites syndrome. Poult Sci. 2003;82(9):1383-7.

\section{Tables}

Table 1. Feed formulation and composition used in both the floor and hypobaric chamber trials for the three feed phases.

\begin{tabular}{|c|c|c|c|c|}
\hline Feed formulation & & & & \\
\hline Ingredient name & Concentration & Starter & Finisher & Withdrawal \\
\hline Corn, yellow & $7.5 \%$ & 55.0 & 61.9 & 67.6 \\
\hline Soybean meal & $47 \%$ & 37.7 & 31.1 & 26.1 \\
\hline Poultry fat & & 3.4 & 3.0 & 2.7 \\
\hline MonoDicalcium Phosphate & & 1.43 & 1.37 & 1.31 \\
\hline Fine limestone & & 1.18 & 1.13 & 1.02 \\
\hline Vitamin Premix & & 0.05 & 0.05 & 0.05 \\
\hline Mineral Premix & & 0.20 & 0.20 & 0.20 \\
\hline Sodium bicarbonate & & 0.13 & 0.16 & 0.19 \\
\hline Sodium chloride & & 0.39 & 0.36 & 0.34 \\
\hline Liquid-Methionine & $88 \%$ & 0.34 & 0.31 & 0.24 \\
\hline L-Lysine $\mathrm{HCl}$ & $78 \%$ & 0.08 & 0.14 & 0.11 \\
\hline Threonine & $98 \%$ & 0.09 & 0.09 & 0.05 \\
\hline Choline & $70 \%$ & 0.10 & 0.10 & 0.08 \\
\hline Total & & 100.0 & 100.0 & 100.0 \\
\hline \multicolumn{5}{|l|}{ Final feed composition } \\
\hline Nutrient & Unit & & & \\
\hline M.E. poultry & $\mathrm{kcal} / \mathrm{kg}$ & 3010 & 3065 & 3113 \\
\hline Protein, crude & $\%$ & 22.5 & 20.0 & 18.0 \\
\hline Fat, crude & $\%$ & 5.1 & 4.9 & 4.7 \\
\hline Calcium & $\%$ & 0.90 & 0.84 & 0.76 \\
\hline Phosphorus, available & $\%$ & 0.45 & 0.42 & 0.38 \\
\hline Sodium & $\%$ & 0.21 & 0.21 & 0.21 \\
\hline Potassium & $\%$ & 1.04 & 0.93 & 0.83 \\
\hline Chloride & $\%$ & 0.30 & 0.30 & 0.28 \\
\hline
\end{tabular}




\begin{tabular}{|c|c|c|c|c|c|c|}
\hline \multicolumn{7}{|c|}{ Ascites } \\
\hline Item & $\mathrm{n}$ & RVTV & No & Yes & Percent, \% & Difference, \% \\
\hline \multicolumn{7}{|c|}{ Hypobaric trial 1} \\
\hline \multicolumn{7}{|l|}{ Sex } \\
\hline Male & 274 & 0.305 & 237 & 37 & 13.50 & \multirow[t]{2}{*}{28.00} \\
\hline Female & 304 & 0.321 & 247 & 57 & 18.75 & \\
\hline \multicolumn{7}{|l|}{ Line } \\
\hline MAS & 332 & 0.310 & 288 & 44 & 13.25 & \multirow[t]{2}{*}{34.83} \\
\hline REL & 246 & 0.318 & 196 & 50 & 20.33 & \\
\hline \multicolumn{7}{|l|}{ Interactions } \\
\hline Male' MAS & 155 & 0.299 & 137 & 18 & 11.61 & \multirow[t]{2}{*}{27.27} \\
\hline Male' REL & 119 & 0.314 & 100 & 19 & 15.97 & \\
\hline Female' MAS & 177 & 0.319 & 151 & 26 & 14.69 & \multirow[t]{2}{*}{39.82} \\
\hline Female' REL & 127 & 0.323 & 96 & 31 & 24.41 & \\
\hline \multicolumn{7}{|l|}{$P$-value } \\
\hline \multicolumn{2}{|l|}{ Sex } & \multicolumn{3}{|l|}{0.009} & \multicolumn{2}{|l|}{0.047} \\
\hline \multicolumn{2}{|l|}{ Genetic Line } & \multicolumn{3}{|l|}{0.160} & \multicolumn{2}{|l|}{0.041} \\
\hline \multicolumn{2}{|l|}{ Sex ' Line } & \multicolumn{3}{|l|}{0.367} & \multicolumn{2}{|l|}{0.742} \\
\hline \multicolumn{7}{|c|}{ Hypobaric Trial 2} \\
\hline \multicolumn{7}{|l|}{ Sex } \\
\hline Male & 186 & 0.387 & 108 & 78 & 41.94 & \multirow[t]{2}{*}{30.47} \\
\hline Female & 247 & 0.421 & 98 & 149 & 60.32 & \\
\hline \multicolumn{7}{|l|}{ Line } \\
\hline MAS & 212 & 0.403 & 108 & 104 & 49.06 & \multirow[t]{2}{*}{11.86} \\
\hline REL & 221 & 0.410 & 98 & 123 & 55.66 & \\
\hline \multicolumn{7}{|l|}{ Interactions } \\
\hline Male' MAS & 91 & 0.39 & 58 & 33 & 36.26 & \multirow[t]{2}{*}{23.44} \\
\hline Male' REL & 95 & 0.39 & 50 & 45 & 47.37 & \\
\hline Female' MAS & 121 & 0.42 & 50 & 71 & 58.68 & \multirow[t]{2}{*}{5.21} \\
\hline Female ' REL & 126 & 0.43 & 48 & 78 & 61.90 & \\
\hline \multicolumn{7}{|l|}{$P$-value } \\
\hline Sex & & $<0.001$ & & & $<0.001$ & \\
\hline Genetic Line & & 0.404 & & & 0.162 & \\
\hline Sex 'Line & & 0.550 & & & 0.415 & \\
\hline
\end{tabular}

1: Drip loss calculated as the difference in breast weight before and after 24 hour chill

\section{Figures}

Page $10 / 20$ 


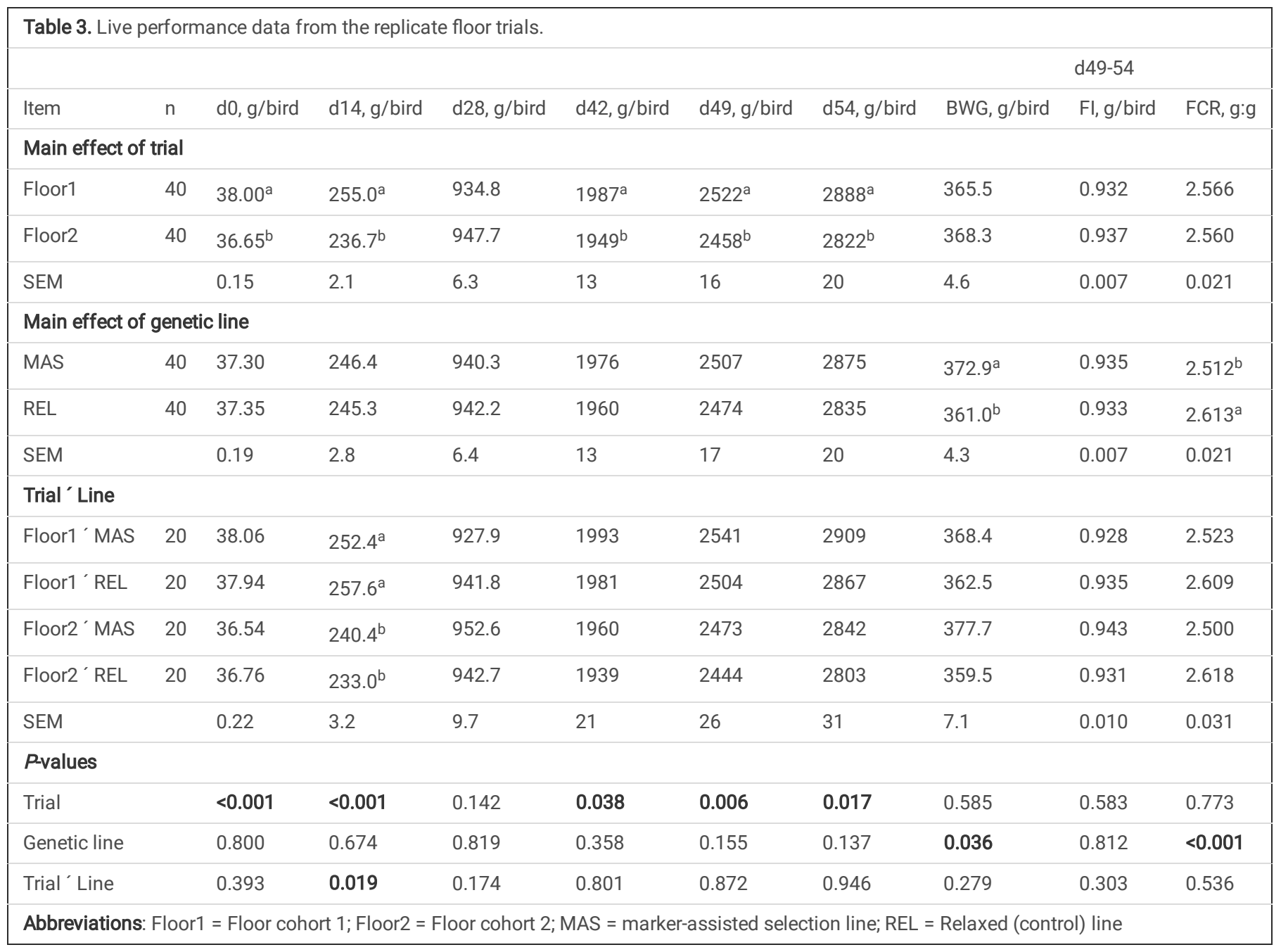


Table 4. Live weight and carcass characteristics from the replicate floor trials.

\begin{tabular}{|c|c|c|c|c|c|c|c|c|}
\hline \multirow[b]{2}{*}{ Item } & \multirow[b]{2}{*}{$\mathrm{n}$} & \multirow{2}{*}{$\begin{array}{l}\text { Live } \\
\text { Weight, kg }\end{array}$} & \multicolumn{2}{|c|}{ Hot carcass } & \multicolumn{2}{|c|}{ Fat pad } & \multicolumn{2}{|c|}{ Chilled carcass } \\
\hline & & & Weight, kg & Yield 1 , \% & Weight, kg & Yield, \% & Weight, kg & Yield, \% \\
\hline \multicolumn{9}{|c|}{ Main effect of trial } \\
\hline Floor1 & 453 & $2814^{\mathrm{a}}$ & $1996^{\mathrm{a}}$ & 70.94 & $67.20^{\mathrm{a}}$ & $2.402^{\mathrm{a}}$ & $2058^{a}$ & 73.13 \\
\hline Floor2 & 415 & $2730^{b}$ & $1941^{b}$ & 71.11 & $59.53^{b}$ & $2.194^{\mathrm{b}}$ & $2002^{b}$ & 73.35 \\
\hline SEM & & 19 & 14 & 0.07 & 0.88 & 0.030 & 14 & 0.07 \\
\hline \multicolumn{9}{|c|}{ Main effect of genetic line } \\
\hline MAS & 439 & $2795^{a}$ & $1988^{a}$ & 71.12 & 64.03 & 2.307 & $2050^{\mathrm{a}}$ & 73.33 \\
\hline REL & 429 & $2752^{b}$ & $1951^{b}$ & 70.91 & 63.00 & 2.297 & $2013^{b}$ & 73.14 \\
\hline SEM & & 19 & 14 & 0.07 & 0.91 & 0.031 & 14 & 0.07 \\
\hline \multicolumn{9}{|c|}{ Main effect of sex } \\
\hline Male & 395 & $3117^{a}$ & $2223^{a}$ & $71.33^{\mathrm{a}}$ & $65.56^{\mathrm{a}}$ & $2.104^{\mathrm{a}}$ & $2281^{a}$ & 73.22 \\
\hline Female & 473 & $2488^{b}$ & $1759^{b}$ & $70.75^{b}$ & $61.81^{b}$ & $2.469^{b}$ & $1823^{b}$ & 73.25 \\
\hline SEM & & 13 & 10 & 0.07 & 0.91 & 0.029 & 10 & 0.08 \\
\hline \multicolumn{9}{|l|}{ Trial' Line } \\
\hline Floor1'MAS & 233 & 2826 & 2010 & 71.09 & 67.00 & 2.385 & 2072 & 73.29 \\
\hline Floor1'REL & 220 & 2803 & 1983 & 70.77 & 67.42 & 2.420 & 2045 & 72.97 \\
\hline Floor2' MAS & 206 & 2761 & 1964 & 71.15 & 60.67 & 2.218 & 2025 & 73.38 \\
\hline Floor2' REL & 209 & 2699 & 1918 & 71.06 & 58.41 & 2.170 & 1979 & 73.33 \\
\hline SEM & & 27 & 20 & 0.10 & 1.36 & 0.045 & 20 & 0.11 \\
\hline \multicolumn{9}{|l|}{ Trial' Sex } \\
\hline Floor1'Male & 204 & $3174^{\mathrm{a}}$ & $2264^{a}$ & 71.29 & $70.71^{a}$ & 2.236 & $2322^{a}$ & 73.13 \\
\hline Floor1' Female & 249 & $2513^{c}$ & $1773^{c}$ & 70.65 & $64.31^{\mathrm{b}}$ & 2.540 & $1838^{c}$ & 73.14 \\
\hline Floor2'Male & 191 & $3055^{b}$ & $2180^{b}$ & 71.38 & $60.07^{c}$ & 1.962 & $2238^{b}$ & 73.32 \\
\hline Floor2' Female & 224 & $2460^{c}$ & $1743^{c}$ & 70.87 & $59.08^{b c}$ & 2.391 & $1806^{c}$ & 73.38 \\
\hline SEM & & 19 & 15 & 0.10 & 1.29 & 0.042 & 15 & 0.11 \\
\hline \multicolumn{9}{|l|}{ Line' Sex } \\
\hline MAS 'Male & 209 & $3147^{a}$ & $2248^{a}$ & 71.42 & 66.98 & 2.128 & $2306^{a}$ & 73.30 \\
\hline MAS 'Female & 230 & $2476^{c}$ & $1753^{c}$ & 70.84 & 61.33 & 2.469 & $1818^{c}$ & 73.36 \\
\hline REL 'Male & 186 & $3085^{b}$ & $2197^{b}$ & 71.23 & 63.95 & 2.076 & $2255^{b}$ & 73.13 \\
\hline REL' Female & 243 & $2498^{c}$ & $1764^{c}$ & 70.67 & 62.27 & 2.468 & $1827^{c}$ & 73.15 \\
\hline SEM & & 21 & 16 & 0.10 & 1.38 & 0.042 & 16 & 0.11 \\
\hline
\end{tabular}

Trial 'Line' Sex

\begin{tabular}{lccc}
\hline Floor1 x MAS x Male & 114 & $2.201^{\mathrm{cd}}$ \\
\hline Floor1 x MAS x Female & 118 & $2.564^{\mathrm{a}}$ \\
\hline Floor1 x REL x Male & 90 & $2.281^{\mathrm{bcd}}$ \\
\hline Floor1 x REL x Female & 127 & $2.518^{\mathrm{ab}}$ \\
\hline Floor2 x MAS x Male & 95 & $2.042^{\mathrm{de}}$ \\
\hline Floor2 x MAS x Female & 111 & $2.369^{\mathrm{abc}}$ \\
\hline Floor2 x REL x Male & 96 & $1.883^{\mathrm{e}}$
\end{tabular}

Page $12 / 20$ 


\begin{tabular}{|c|c|c|c|c|c|c|c|}
\hline Floor2 x REL x Female & 113 & & & & $2.413^{\mathrm{abc}}$ & & \\
\hline SEM & & & & & 0.062 & & \\
\hline \multicolumn{8}{|l|}{$P$-values } \\
\hline Trial & $<0.001$ & $<0.001$ & 0.078 & $<0.001$ & $<0.001$ & $<0.001$ & 0.270 \\
\hline Genetic line & 0.008 & 0.003 & 0.054 & 0.313 & 0.618 & 0.003 & 0.069 \\
\hline Sex & $<0.001$ & $<0.001$ & $<0.001$ & 0.002 & $<0.001$ & $<0.001$ & 0.640 \\
\hline Trial' Line & 0.235 & 0.432 & 0.293 & 0.274 & 0.349 & 0.468 & 0.174 \\
\hline Trial' Sex & 0.035 & 0.028 & 0.514 & 0.019 & 0.108 & 0.036 & 0.909 \\
\hline Line' Sex & 0.011 & 0.012 & 0.942 & 0.200 & 0.628 & 0.019 & 0.915 \\
\hline Trial 'Line' Sex & 0.980 & 0.992 & 0.637 & 0.093 & 0.039 & 0.963 & 0.889 \\
\hline
\end{tabular}

Abbreviations: Floor1 = Floor cohort 1; Floor2 = Floor cohort 2; MAS = marker-assisted selection line; REL = Relaxed (control) line

1: Yields calculated based on back-dock live weight

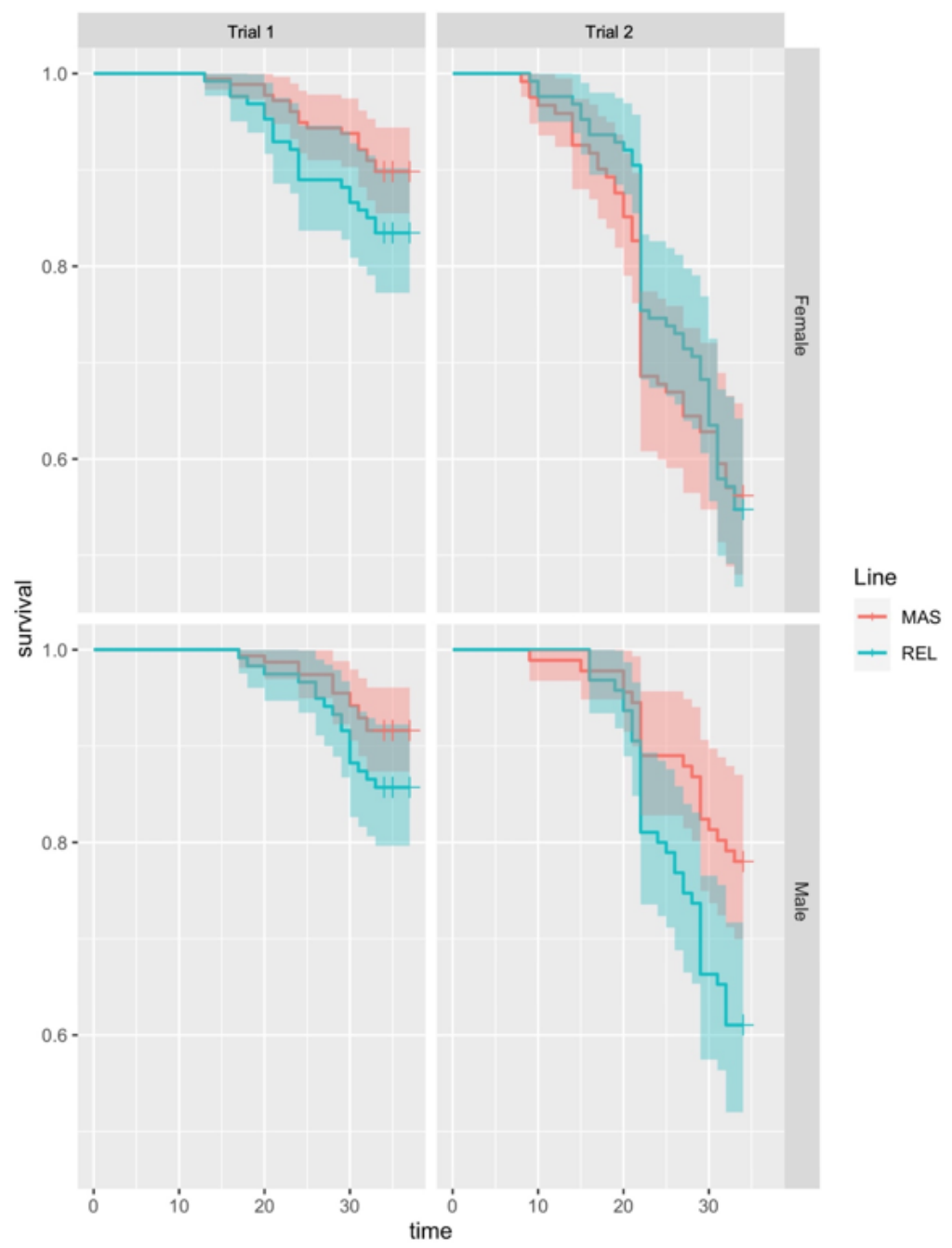

\section{Figure 1}

Survival plots for the two hypobaric chamber challenges comparing the MAS and REL lines according to sex. 
Table 5. Deboned parts characteristics from the replicate floor trials.

Wings Breast fillets

Item

(n)

n $\quad \begin{aligned} & \text { Weight, } \\ & \text { kg }\end{aligned}$ Yield $^{1}, \%$

Weight, Yield, \%

$\mathrm{kg}$
Tenders

Weight, Yield, \%

$\mathrm{kg}$
Thighs

Weight, Yield, \%

kg
Drumsticks

Weight, Yield, \% $\mathrm{kg}$

\section{Main effect of trial}

\begin{tabular}{|c|c|c|c|c|c|c|c|c|c|c|c|}
\hline Floor1 & 453 & $223.2^{\mathrm{a}}$ & 7.947 & 431.6 & $15.33^{b}$ & 112.2 & $4.001^{b}$ & $380.4^{a}$ & $13.47^{a}$ & $271.9^{a}$ & $9.653^{a}$ \\
\hline Floor2 & 415 & $216.6^{b}$ & 7.936 & 432.4 & $15.79^{a}$ & 111.2 & $4.080^{a}$ & $362.7^{b}$ & $13.25^{\mathrm{b}}$ & $260.3^{b}$ & $9.537^{b}$ \\
\hline SEM & & 1.5 & 0.020 & 3.7 & 0.07 & 0.8 & 0.020 & 3.3 & 0.05 & 2.1 & 0.027 \\
\hline
\end{tabular}

\section{Main effect of genetic line}

\begin{tabular}{|c|c|c|c|c|c|c|c|c|c|c|c|}
\hline MAS & 439 & 221.2 & 7.928 & 435.9 & 15.57 & $114.0^{\mathrm{a}}$ & $4.091^{a}$ & $376.3^{a}$ & 13.41 & $269.8^{a}$ & $9.649^{a}$ \\
\hline REL & 429 & 218.9 & 7.956 & 427.9 & 15.54 & $109.5^{\mathrm{b}}$ & $3.985^{\mathrm{b}}$ & $367.5^{b}$ & 13.31 & $262.9^{b}$ & $9.546^{b}$ \\
\hline SEM & & 1.5 & 0.020 & 3.7 & 0.07 & 0.8 & 0.018 & 3.3 & 0.05 & 2.1 & 0.027 \\
\hline
\end{tabular}

\section{Main effect of sex}

\begin{tabular}{|c|c|c|c|c|c|c|c|c|c|c|c|}
\hline Male & 395 & $247.5^{a}$ & 7.943 & $483.2^{a}$ & 15.49 & $121.8^{a}$ & $3.907^{b}$ & $427.6^{a}$ & $13.71^{a}$ & $302.7^{a}$ & $9.723^{a}$ \\
\hline Female & 473 & $197.2^{b}$ & 7.940 & $389.1^{b}$ & 15.60 & $103.3^{b}$ & $4.149^{a}$ & $325.4^{b}$ & $13.07^{b}$ & $236.2^{b}$ & $9.494^{\mathrm{b}}$ \\
\hline SEM & & 1.0 & 0.019 & 3.2 & 0.07 & 0.7 & 0.018 & 2.5 & 0.05 & 1.5 & 0.027 \\
\hline \multicolumn{12}{|l|}{ Trial' Line } \\
\hline Floor1' MAS & 233 & 224.1 & 7.925 & 436.7 & 15.37 & 114.4 & 4.057 & 383.5 & 13.53 & 274.7 & 9.717 \\
\hline Floor1' REL & 220 & 222.2 & 7.970 & 426.1 & 15.29 & 110.0 & 3.941 & 377.4 & 13.39 & 269.1 & 9.586 \\
\hline Floor2' MAS & 206 & 217.9 & 7.932 & 435.0 & 15.79 & 113.5 & 4.130 & 368.2 & 13.27 & 264.1 & 9.571 \\
\hline Floor2' REL & 209 & 215.4 & 7.940 & 429.8 & 15.80 & 108.9 & 4.031 & 357.1 & 13.22 & 256.5 & 9.504 \\
\hline SEM & & 2.2 & 0.029 & 5.3 & 0.10 & 1.2 & 0.029 & 4.7 & 0.08 & 3.0 & 0.040 \\
\hline
\end{tabular}

\section{Trial' Sex}

\begin{tabular}{|c|c|c|c|c|c|c|c|c|c|c|c|}
\hline Floor1'Male & 204 & 252.1 & 7.938 & 486.7 & 15.34 & $123.6^{a}$ & $3.899^{c}$ & $439.6^{a}$ & 13.85 & $310.2^{a}$ & 9.779 \\
\hline Floor1' Female & 249 & 199.4 & 7.954 & 386.2 & 15.33 & $102.7^{c}$ & $4.084^{b}$ & $330.9^{c}$ & 13.15 & $240.0^{c}$ & 9.550 \\
\hline Floor2'Male & 191 & 242.5 & 7.949 & 479.4 & 15.66 & $119.9^{b}$ & $3.915^{\mathrm{c}}$ & $414.8^{b}$ & 13.57 & $294.7^{b}$ & 9.662 \\
\hline Floor2'Female & 224 & 194.7 & 7.925 & 392.3 & 15.90 & $104.0^{c}$ & $4.220^{a}$ & $319.3^{d}$ & 12.97 & $231.9^{d}$ & 9.433 \\
\hline SEM & & 1.3 & 0.029 & 4.7 & 0.10 & 1.1 & 0.027 & 3.6 & 0.08 & 2.0 & 0.038 \\
\hline \multicolumn{12}{|l|}{ Line' Sex } \\
\hline MAS' Male & 209 & 248.8 & 7.911 & $489.8^{a}$ & 15.53 & 124.2 & 3.944 & $434.2^{\mathrm{a}}$ & 13.79 & $306.8^{a}$ & 9.765 \\
\hline MAS'Female & 230 & 196.3 & 7.944 & $387.0^{\mathrm{b}}$ & 15.60 & 104.7 & 4.225 & $323.7^{c}$ & 13.07 & $236.4^{c}$ & 9.544 \\
\hline REL'Male & 186 & 246.0 & 7.980 & $475.8^{a}$ & 15.45 & 119.4 & 3.865 & $420.6^{b}$ & 13.63 & $298.5^{b}$ & 9.675 \\
\hline REL'Female & 243 & 198.0 & 7.937 & $391.0^{b}$ & 15.61 & 101.8 & 4.076 & $326.7^{c}$ & 13.06 & $235.7^{c}$ & 9.447 \\
\hline SEM & & 1.7 & 0.028 & 5.0 & 0.11 & 1.1 & 0.026 & 3.7 & 0.08 & 2.3 & 0.041 \\
\hline
\end{tabular}

\section{Pvalues}

\begin{tabular}{|c|c|c|c|c|c|c|c|c|c|c|}
\hline Trial & $<0.001$ & 0.630 & 0.834 & $<0.001$ & 0.296 & $<0.001$ & $<0.001$ & $<0.001$ & $<0.001$ & 0.002 \\
\hline Genetic line & 0.840 & 0.286 & 0.324 & 0.665 & $<0.001$ & $<0.001$ & 0.003 & 0.258 & $<0.001$ & 0.016 \\
\hline Sex & $<0.001$ & 0.773 & $<0.001$ & 0.180 & $<0.001$ & $<0.001$ & $<0.001$ & $<0.001$ & $<0.001$ & $<0.001$ \\
\hline Trial' Line & 0.085 & 0.393 & 0.698 & 0.532 & 0.924 & 0.631 & 0.404 & 0.897 & 0.564 & 0.563 \\
\hline Trial' Sex & 0.053 & 0.558 & 0.079 & 0.210 & 0.010 & 0.014 & 0.025 & 0.481 & 0.032 & 0.903 \\
\hline Line' Sex & 0.213 & 0.185 & 0.050 & 0.538 & 0.339 & 0.127 & 0.006 & 0.287 & 0.032 & 0.842 \\
\hline Trial' Line' Sex & 0.245 & 0.073 & 0.568 & 0.441 & 0.725 & 0.668 & 0.607 & 0.251 & 0.906 & 0.827 \\
\hline
\end{tabular}


Abbreviations: Floor1 = Floor cohort 1; Floor2 = Floor cohort 2; MAS = marker-assisted selection line; REL = Relaxed (control) line

1: Yields calculated based on back-dock live weight

Page $15 / 20$ 


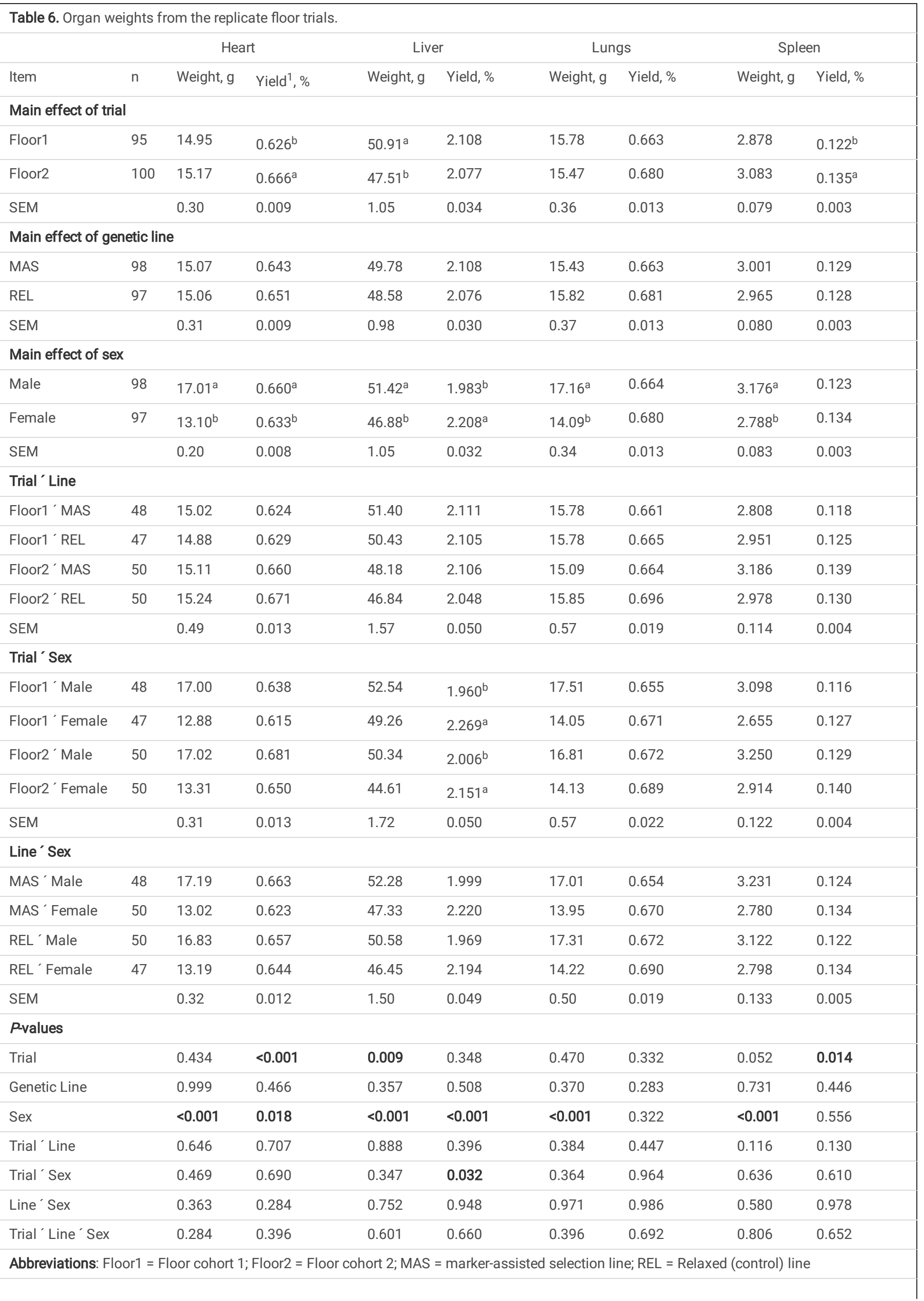


1: Yields calculated based on back-dock live weight

Page $17 / 20$ 


\begin{tabular}{|c|c|c|c|c|}
\hline Item & $\mathrm{n}$ & $\mathrm{RV}$ & TV & RV:TV \\
\hline \multicolumn{5}{|l|}{ Main effect of trial } \\
\hline Floor1 & 95 & 2.306 & 10.31 & $0.225^{\mathrm{a}}$ \\
\hline Floor2 & 100 & 2.270 & 10.43 & $0.217^{b}$ \\
\hline SEM & & 0.056 & 0.22 & 0.003 \\
\hline \multicolumn{5}{|c|}{ Main effect of genetic line } \\
\hline MAS & 98 & 2.284 & 10.40 & 0.220 \\
\hline REL & 97 & 2.292 & 10.34 & 0.222 \\
\hline SEM & & 0.059 & 0.22 & 0.003 \\
\hline \multicolumn{5}{|l|}{ Main effect of sex } \\
\hline Male & 98 & $2.589^{a}$ & $11.85^{\mathrm{a}}$ & 0.219 \\
\hline Female & 97 & $1.986^{\mathrm{b}}$ & $8.87^{b}$ & 0.223 \\
\hline SEM & & 0.044 & 0.14 & 0.003 \\
\hline \multicolumn{5}{|l|}{ Trial ' Line } \\
\hline Floor1' MAS & 48 & $2.354^{a}$ & 10.41 & $0.230^{\mathrm{a}}$ \\
\hline Floor1'REL & 47 & $2.259^{a}$ & 10.20 & $0.220^{\mathrm{ab}}$ \\
\hline Floor2'MAS & 50 & $2.218^{a}$ & 10.40 & $0.210^{\mathrm{a}}$ \\
\hline Floor2'REL & 50 & $2.323^{a}$ & 10.46 & $0.224^{\mathrm{ab}}$ \\
\hline SEM & & 0.091 & 0.36 & 0.005 \\
\hline \multicolumn{5}{|l|}{ Trial' Sex } \\
\hline Floor1'Male & 48 & 2.618 & 11.96 & 0.221 \\
\hline Floor1' Female & 47 & 1.995 & 8.64 & 0.230 \\
\hline Floor2'Male & 50 & 2.562 & 11.76 & 0.218 \\
\hline Floor2' Female & 50 & 1.979 & 9.09 & 0.216 \\
\hline SEM & & 0.066 & 0.21 & 0.004 \\
\hline \multicolumn{5}{|l|}{ Line'Sex } \\
\hline MAS 'Male & 48 & 2.609 & 12.04 & 0.218 \\
\hline MAS ' Female & 50 & 1.978 & 8.83 & 0.221 \\
\hline REL'Male & 50 & 2.571 & 11.68 & 0.220 \\
\hline REL' Female & 47 & 1.995 & 8.91 & 0.224 \\
\hline SEM & & 0.075 & 0.24 & 0.005 \\
\hline \multicolumn{5}{|l|}{$P$-values } \\
\hline Trial & & 0.538 & 0.499 & 0.049 \\
\hline Genetic Line & & 0.802 & 0.712 & 0.517 \\
\hline Sex & & $<0.001$ & $<0.001$ & 0.481 \\
\hline Trial' Line & & 0.046 & 0.489 & 0.005 \\
\hline Trial' Sex & & 0.691 & 0.078 & 0.192 \\
\hline Line'Sex & & 0.630 & 0.237 & 0.862 \\
\hline Trial ' Line' Sex & & 0.907 & 0.154 & 0.075 \\
\hline
\end{tabular}




\begin{tabular}{|c|c|c|c|c|c|c|c|c|c|}
\hline \multirow[b]{2}{*}{ Item } & \multirow[b]{2}{*}{$\mathrm{n}$} & \multirow[b]{2}{*}{ Drip loss ${ }^{1}, \mathrm{~g}$} & \multicolumn{3}{|c|}{ 24-hr Color } & \multirow[b]{2}{*}{ 24-hr pH } & \multicolumn{2}{|r|}{ Shear } & \multirow[b]{2}{*}{ Peaks } \\
\hline & & & $L *(D 65)$ & $a^{\star}(D 65)$ & $b^{\star}(D 65)$ & & Force $(\mathrm{N})$ & Area 1:3 & \\
\hline \multicolumn{10}{|c|}{ Main effect of trial } \\
\hline Floor1 & 198 & 2.052 & 52.34 & $2.050^{\mathrm{a}}$ & $8.932^{\mathrm{a}}$ & $5.946^{\mathrm{a}}$ & 14.04 & 187.7 & $8.823^{b}$ \\
\hline Floor2 & 197 & 2.165 & 52.72 & $1.776^{b}$ & $8.607^{b}$ & $5.857^{b}$ & 14.26 & 191.9 & $9.545^{\mathrm{a}}$ \\
\hline SEM & & 0.116 & 0.19 & 0.071 & 0.108 & 0.013 & 0.23 & 2.7 & 0.182 \\
\hline \multicolumn{10}{|c|}{ Main effect of genetic line } \\
\hline MAS & 196 & 2.161 & $53.03^{a}$ & $1.805^{\mathrm{b}}$ & $8.956^{a}$ & $5.875^{\mathrm{b}}$ & $13.85^{\mathrm{b}}$ & $184.0^{\mathrm{b}}$ & 8.981 \\
\hline REL & 199 & 2.047 & $52.04^{\mathrm{b}}$ & $2.011^{\mathrm{a}}$ & $8.582^{b}$ & $5.926^{a}$ & $14.45^{\mathrm{a}}$ & $195.6^{a}$ & 9.384 \\
\hline SEM & & 0.114 & 0.19 & 0.069 & 0.107 & 0.013 & 0.22 & 2.6 & 0.179 \\
\hline \multicolumn{10}{|c|}{ Main effect of sex } \\
\hline Male & 198 & $1.612^{\mathrm{b}}$ & $51.50^{\mathrm{b}}$ & 1.923 & $8.384^{b}$ & $5.935^{\mathrm{a}}$ & $13.76^{\mathrm{b}}$ & $186.0^{\mathrm{b}}$ & $8.859^{b}$ \\
\hline Female & 197 & $2.617^{a}$ & $53.56^{a}$ & 1.893 & $9.157^{a}$ & $5.866^{b}$ & $14.55^{\mathrm{a}}$ & $193.7^{a}$ & $9.512^{\mathrm{a}}$ \\
\hline SEM & & 0.125 & 0.18 & 0.071 & 0.106 & 0.013 & 0.22 & 2.7 & 0.187 \\
\hline \multicolumn{10}{|l|}{ Trial ' Line } \\
\hline Floor1' MAS & 97 & 2.117 & 52.89 & 1.905 & 9.093 & 5.925 & $14.32^{\mathrm{ab}}$ & $189.1^{b}$ & 8.521 \\
\hline Floor1' REL & 101 & 1.990 & 51.79 & 2.190 & 8.774 & 5.966 & $13.78^{b}$ & $186.5^{b}$ & 9.113 \\
\hline Floor2' MAS & 99 & 2.204 & 53.16 & 1.706 & 8.821 & 5.825 & $13.39^{b}$ & $179.0^{\mathrm{b}}$ & 9.427 \\
\hline Floor2' REL & 98 & 2.106 & 52.30 & 1.824 & 8.389 & 5.885 & $15.14^{\mathrm{a}}$ & $204.9^{a}$ & 9.667 \\
\hline SEM & & 0.166 & 0.27 & 0.103 & 0.155 & 0.018 & 0.33 & 3.9 & 0.268 \\
\hline \multicolumn{10}{|l|}{ Trial' Sex } \\
\hline Floor1'Male & 101 & 1.460 & 51.12 & 2.152 & 8.469 & 5.980 & $13.28^{b}$ & $180.4^{b}$ & 8.441 \\
\hline Floor1' Female & 97 & 2.696 & 53.56 & 1.945 & 9.414 & 5.910 & $14.83^{\mathrm{a}}$ & $195.3^{a}$ & 9.229 \\
\hline Floor2'Male & 97 & 1.771 & 51.89 & 1.682 & 8.295 & 5.888 & $14.26^{\mathrm{ab}}$ & $191.9^{\mathrm{ab}}$ & 9.299 \\
\hline Floor2' Female & 100 & 2.542 & 53.56 & 1.842 & 8.908 & 5.822 & $14.28^{\mathrm{ab}}$ & $192.1^{\mathrm{ab}}$ & 9.783 \\
\hline SEM & & 0.179 & 0.27 & 0.113 & 0.149 & 0.019 & 0.33 & 3.9 & 0.290 \\
\hline \multicolumn{10}{|l|}{ Line'Sex } \\
\hline MAS ' Male & 98 & 1.670 & 51.80 & 1.855 & $8.411^{\mathrm{b}}$ & 5.916 & 13.62 & 180.7 & 8.699 \\
\hline MAS ' Female & 98 & 2.663 & 54.25 & 1.754 & $9.506^{\mathrm{a}}$ & 5.833 & 14.09 & 187.3 & 9.265 \\
\hline REL'Male & 100 & 1.556 & 51.20 & 1.992 & $8.356^{b}$ & 5.954 & 13.91 & 191.3 & 9.018 \\
\hline REL'Female & 99 & 2.570 & 52.88 & 2.029 & $8.811^{\mathrm{b}}$ & 5.898 & 15.01 & 200.0 & 9.758 \\
\hline SEM & & 0.178 & 0.26 & 0.104 & 0.156 & 0.019 & 0.32 & 4.0 & 0.264 \\
\hline \multicolumn{10}{|l|}{$P$-values } \\
\hline Trial & & 0.629 & 0.113 & 0.003 & 0.017 & $<0.001$ & 0.457 & 0.239 & 0.002 \\
\hline Genetic Line & & 0.515 & $<0.001$ & 0.037 & 0.009 & 0.003 & 0.045 & 0.001 & 0.060 \\
\hline Sex & & $<0.001$ & $<0.001$ & 0.803 & $<0.001$ & $<0.001$ & 0.009 & 0.031 & 0.016 \\
\hline Trial ' Line & & 0.908 & 0.611 & 0.367 & 0.757 & 0.622 & $<0.001$ & $<0.001$ & 0.378 \\
\hline Trial' Sex & & 0.128 & 0.112 & 0.052 & 0.236 & 0.848 & 0.010 & 0.040 & 0.681 \\
\hline Line' Sex & & 0.967 & 0.112 & 0.456 & 0.025 & 0.473 & 0.287 & 0.778 & 0.555 \\
\hline Trial 'Line' Sex & & 0.096 & 0.794 & 0.290 & 0.694 & 0.766 & 0.803 & 0.956 & 0.667 \\
\hline
\end{tabular}


Abbreviations: Floor1 = Floor cohort 1; Floor2 = Floor cohort 2; MAS = marker-assisted selection line; REL = Relaxed (control) line 